\title{
Exchange Rate Misalignment And Current Account Sustainability: The Australian Experience
}

François Hermet (E-mail: fhermet@univ-reunion.fr), University of La Réunion, France Jean-François Hoarau (E-mail: jean-francois.hoarau@voila.fr), University of La Réunion, France Alain Nurbel (E-mail: nurbel@univ-reunion.fr), University of La Réunion, France

\begin{abstract}
Australia's persistent current account deficit engenders lively debates about its intertemporal solvency. This paper aims at showing whether there is really a misalignment of the $\$ A$ real effective exchange rate ( $\$ A$ REER) and, if it is the case, at wondering about its real influence on the current account of Australia. The estimation of our empirical model puts forward a misalignment of the $\$ A$ REER, but at the same time allows to emphasise the reduction in the magnitude of the misalignment since the adoption of the flexible exchange rate regime. Adding the stabilisation of the current account deficit, although recurrent, results in lending support to the Australian current account sustainability commonly held view.
\end{abstract}

\section{Introduction}

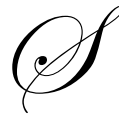

ince the eighties, Australia's current account deficit (CAD) varies between $-4 \%$ and $-2 \%$ of the gross domestic product (GDP), with the trend of the beginning of 2000s being located around $-4 \%$ of the GDP. This disturbing and deepening CAD is dangerous insofar as it is likely to threat Australia's intertemporal solvency. By definition, solvency for an economy means that the net present value of its trade surpluses equals its current external indebtedness. According to Leachman and Thorpe (1998), Australia faces a latent problem of solvency as no long run cointegration relation can be found between its exports and its imports over 1984-1996. No such problem arises over 1959-1983, which is a period of fixed exchange rate regime, given up on December 1983 in favour of the floating exchange rate regime.

In a synthesis on Australian economic policy in the course of 1980s and 1990s, Svizzero (2001) recalls that Australia's external trade structure belongs to a set of factors often quoted to explain its CAD. Indeed, Australia is a great exporter of non-agricultural intermediary products, whose prices are fixed on the world market and tend to lessen. Also is Australia a great importer of industrialised goods, whose increasing prices do not impact on the level of Australia's demand. So, given its external trade structure on one hand, the high price elasticity of the world demand for its exports and the price inelasticity of domestic demand for imports on the other hand, the terms of trade of Australia tend to worsen, resulting in widening its CAD. Unfortunately, the author pays little attention to the impact a possible misalignment of the Australian dollar real effective exchange rate (\$A REER) may have on Australia's CAD.

However, it seems interesting to move from the economic specialisation approach towards the current account sustainability framework. Indeed, a CAD in not dangerous as long as it can be sustainable. The real exchange rate overvaluation ranks among the set of indicators which are used to lean on when appraising the current account sustainability is at work (Kaminsky, Lizondo et Reinhart, 1997). Then, the persistent CAD of Australia leads to search for the influence of a possible misalignment of the \$A REER. Indeed, on 1970-2000, it can be noticed that each phase of strong appreciation of the \$A REER is followed by a phase of strong depreciation (Chart 2 ), resulting in lending support to the thesis according to which the Australian dollar sticks to a trajectory around its long term equilibrium value. In addition, putting the \$A REER and the Australian current account together seems to 
bring forth a problem of price-competitiveness. Indeed, the strong REER appreciation between 1980 and 1984 proceeds along with a deterioration of the Australian's current account. The same pattern occurs over 1986-1989 and 1993-1997.

The rest of the paper runs as follows. We set out a specification of the empirical model and we make the preliminary tests (2). Then we estimate (3) and we draw the misalignment of the \$A REER from these estimations (4). Finally, we conclude (5).

\section{Specifying An Empirical Model And Preliminary Tests}

The real misalignment of a currency is defined as the constant gaps of the real exchange rate compared with its fundamental long term value. In other words, it results from the difference between the current real exchange rate, i.e. the rate observed, and the equilibrium real exchange rate. Consequently, it clearly appears that putting forward the real misalignment highly depends upon the definition and the determination of a standard for the equilibrium real exchange rate. The last twenty years show how much this topic matters (Williamson, 1983, 1985, 1994; Edwards, 1989, 1994; Stein, 1994, 1995; Clark and MacDonald, 1998; Hinkle and Montiel, 1999). Drawing on the existing research allows to point out the most relevant determinants ${ }^{1}$ of the real misalignment, namely the total productivity $(u)$, the terms of trade $($ tot $)$, the preference for the present $(\rho)$, the public expenditure $(\bar{g})$, the foreign demand $\left(y_{w}\right)$, the degree of openness $(o p)$ and world real interest rate $\left(r_{w}\right)$. We do not reconsider the conceptual analysis but we rather propose to determine it in an empirical way.

\subsection{Model Specification}

The estimed model is based on two relations yielding the \$A REER and its real fundamental determining factors : a long term stationary state relation (1) and a short term relation dedicated to the short run dynamics and the self-correcting mechanisms allowing convergence towards the stationary state (2). Then we have :

$\ln e_{t}=\beta^{\prime} \ln z_{t}+\varsigma_{t}$

where $z=\left[t o t, u, \rho, \bar{g}, y_{w}, o p, r_{w}\right]$ 'representing the vector of the fundamental determinants and $\varsigma_{t}$ a random walk independently and identically distributed identically. The long term equilibrium real exchange rate $\left(e^{*}\right)$ results from this one by replacing in (1) the fundamental determinants by their sustainable values $(z p)$, i.e. values free of the cyclical disturbances, resulting in : $\ln e^{*}=\beta^{\prime} \ln z^{p}$.

$\Delta \ln e_{t}=\alpha\left(\ln e_{t-1}-\beta^{\prime} \ln z_{t-1}\right)+\sum_{j=1}^{p} \kappa_{t} \Delta \ln e_{t-j}+\sum_{j=0}^{p} \lambda^{\prime} \Delta \ln z_{t-j}+v_{t}$

with $\Delta$ the operator of differences, $v_{t}$ a random walk independently and identically distributed and $\left.\alpha \in\right]-2,0[$ so that the long run equilibrium is stable (Baffes, Elbadawi and O' Connell, 1999). It is this relation which is to be estimed for Australia taking quartely data over 1976-2000. The econometric determination of (2) requires to know the long term relation between the real exchange rate and the fundamental variables on one hand, the short run dynamics along with the long term equilibrium on the other hand.

\footnotetext{
1 Proxies are used to appraise some theoretical variables. Then, the global productivity is given by the real gross domestic product per capita, the preference for the present by total absorption and private consumption, the foreign demand by American and Japanese imports and the world real interest rate by the American real interest rate. In addition, the real exchange rate is computed as an real effective exchange rate.

The real effective exchange rate is provided by the JP Morgan index, while the other variables are drawn from the IFS base of the IMF.
} 


\subsection{Stationarity And Cointegration Tests}

A long term relation between several variables is likely to exist, provided that two conditions are gathered. First, the variables must be non stationary and integrated to the same order. Second, their stochastic trends must depend upon each other, meaning that one or several stationary linear combinations of these non stationary variables may exist.

Then, we are to find first the integration order of these variables relying on unit roots tests. The PhillipsPerron test (1988) is used considering stationary as the null hypothesis for three models, namely a first one with trend and constant (model 1), a second one without trend but with constant (model 2), a third one both without trend and constant (model 3). The results for the variables in level (Table 1) show that the non stationary null hypothesis is rejected to the 5\% threshold for the public expenditures, the public debt, the real price of imports, the degree of openness and the real interest rate differential. The same operation is implemented for the variables in first differences to know if the non stationary variables are integrated to the first order. Once again, the non stationary null hypothesis is rejected to the 5\% threshold for all the variables in first differences ${ }^{2}$. According to the results of the PP test, a cointegration relation is likely to exist between the real exchange rate and the real fundamentals like the GDP per capita, the total domestic absorption, the private consumption, the domestic investment, the terms of trade, the American demand, the Japanese demand and the American real interest rate ${ }^{3}$.

In a second stage, we lean on a cointegration test to bring forth the number of cointegration relations linking the non stationary variables. To serve this goal, the maximum likelihood method is adopted (Enders, 1995; Johansen, 1991). This method rests on a VAR with order $\mathrm{p}$ which runs as follows:

$y_{t}=A_{1} y_{t-1}+\ldots+A_{p} y_{t-p}+B x_{t}+U_{t}$

where $y_{t}$ is a vector of the non stationary variables I(1) with size $1 \times k, x_{t}$ a vector of the deterministic variables with size $1 \times d, U_{t}$ a vector of innovations with size $1 \times k$ and $A_{1}$ to $A_{P}$ the matrices of coefficients with size $k \times k$. It is possible to write (3) in another way so that :

$\Delta y_{t}=\Pi y_{t-1}+\sum_{i=1}^{p-1} \Gamma_{i} \Delta y_{t-i}+B x_{t}+U_{t}$

where $\Pi=\sum_{i=1}^{p} A_{i}-I ; \Gamma_{i}=-\sum_{j=i+1}^{p} A_{j}$ and $I$ representing the matrix identity. According to Granger representation theorem, if the matrix of coefficients has a reduced rank $\mathrm{r}$ (with $0<r<1$ ), then it can be divided into two matrix $\Omega_{\square} \square$ and $\Omega_{2}$ with size $k \times r$ so that $\Pi=\Omega_{1} \cdot \Omega_{2}{ }^{\prime}$ and $\Omega_{2} y_{t}$ is stationary. $\Omega \square \square$ and $\Omega 2$ respectively represent the matrix of error correction coefficients (i.e. the matrix of the adjustment parameters) and the matrix of the cointegrating vectors.

The Johansen method estimates the $\operatorname{VAR}(p=1)^{4}$ under the constraint $\Pi=\Omega_{1} \cdot \Omega_{2}{ }^{\prime}$, giving different values to $r$ by maximum likelihood. Taking this estimation into account, Johansen proposes a test on the rank, i.e. the Trace test, which allows to know with accuracy the number of cointegration relations between endogenous variables belonging to $y_{t}$. We apply the Johansen test on the VAR (1) which comprises the real effective exchange rate, the terms of trade, the American demand, the Japanese demand, the national private consumption and the American real

2 These results are confirmed by the ADF tests.

3 However, the influence of the variables $\mathrm{I}(0)$, i.e. the stationary fundamentals in level, should not be neglected in the study of the short run dynamics.

4 Before this step, we must determine the optimal lag of the VAR. We estimate several specifications of the VAR by taking different order of lag for each of them. We choose the specification which minimises the Schwarz («SB ») and the Akaike (« AIC ) criteria. These one advocate to take $\mathrm{p}=1$ as optimal lag (Table 3 ). 
interest rate. The number of cointegrating vectors is given by the Johansen Trace statistic. Then, we test the null hypothesis $\left(H_{0}\right.$ : there is at best $r$ vectors of cointegration) versus the alternative hypothesis ( $H_{1}$ : there is at least $r$ vectors of cointegration) in a sequential way from $r=0$ to $r=k+1$. As a result, we first test the hypothesis that the number of cointegration vectors strictly equals $0(r=0)$ (LR Column, table 4). We notice that the Trace statistic when $\mathrm{r}=0$ (158.37) is higher than the critical values to $1 \%$ (137.57) and to 5\% (124.24) providing ground to reject $H_{0}$. Second, we test the hypothesis according to which the number of cointegration vectors strictly equals 1 . The Trace statistic when $r=1$ (100.11) is higher than the critical value to $1 \%$ (94.15) and lower than the critical value to 5\% (103.18), resulting in accepting $H_{0}$ to the 5\% threshold. Then, we can conclude that there is at least and at best a cointegration relation between the variables.

Before we estimate the equilibrium real exchange rate, we must check that the single cointegration relation is really a real exchange rate equation and, as a result, the other variables, i.e. the real fundamental determinants, are weakly exogenous. A test of exogeneity can be carried out by taking the estimation of a $\operatorname{VECM}(1)$ through the Johansen method:

$\Delta y_{t}=\Pi y_{t-1}+\Gamma_{1} \delta y_{t-1}+U_{t}$

where $y_{t}$ is a vector with size $6 \times 1$ comprising the real exchange rate, the terms of trade, the American demand, the Japanese demand, the national private consumption and the domestic investment, $\Gamma_{1}$ the $6 \times 6$ matrix of coefficients and $U_{t}$ the $6 \times 1$ vector of innovations.

All in all, the model exhibits good statistical properties (Table 5). First, the PP test shows that the residues are stationary in level around zero to the 5\% threshold. Second, the Breusch-Godfrey LM test of order 2 and 4 indicates that the residues are not self-correlated, except in the case of the third and the forth equations to 4 order. Finally, the Jarque-Berra test sustains that the residues are distributed according to a normal law except for the second and the sixth equations. According to the results pertaining to the test of the weak exogeneity hypothesis by resting on the parameters associated with the cointegration vector, i.e. the adjustment speeds located within the vector error correction model, the above cointegration relation is really a real exchange rate equation. Indeed, the single statistically significant adjustment parameter of the model belongs to the first equation ${ }^{5}$. Consequently, it can be conclude that the terms of trade, the Japanese demand, the American demand, the American real interest rate, the preference for the present and the global productivity are weakly exogenous.

\section{Estimating The Long Term And Short Term Relations}

\subsection{Results For The Long Term Relation}

A simple way in estimating the long run relation linking the real exchange rate and its real fundamentals is to apply the OLS method to the following regression (Engle-Granger, 1987):

$e_{t}=\mu_{0}+a_{1}$ tot $_{1}+a_{2} y_{t}^{j a p}+a_{3} y_{t}^{u s a}+a_{4} r_{t}^{w}+a_{5} \rho_{t}+a_{6} u_{t}+U_{t}$

where the terms $a_{i}, i=1, \ldots, 6$ are the long run parameters. Nevertheless, although the OLS estimations on a regression like (6) are super-convergent when all the variables are really cointegrated, these one do not exhibit good properties in the case of finite samples, i.e. the estimations are skewed (Davidson and MacKinnon, 1993). However, it is possible to evolve the estimations by applying simple correction procedures to (6). It is shown that (Stock and Watson, 1988; Saikkonen, 1991) asymptotically effective estimations may be reached by doing the following regression by means of the least squares:

$e_{t}=\mu_{0}+a_{1} t o t_{1}+a_{2} y_{t}^{j a p}+a_{3} y_{t}^{u s a}+a_{4} r_{t}^{w}+a_{5} \rho_{t}+a_{6} u_{t}+Z_{t}+U_{t}$

5 The parameter associated with equation 5 is also statistically significant but given that it is higher than 2, it cannot be considered as a good recall term in the case of a stationary relation. 
where $Z_{t}=\sum_{j=-p}^{p} C_{j} . \Delta y_{t-1}^{f}$ et $y_{t}^{f}$ represent the set of the fundamental determinants of the real exchange rate. This equation simply adds the $p$ advances and the $p$ lags of the first differences of $y_{t}^{f}$ to the regression (6). This change makes it possible to get unbiased estimators and to tap the $t$ student associated with each estimators. The results are provided by the table 6 . Then, in the long run, an increase in the terms of trade, the Japanese demand, the global productivity and the American real interest rate engenders a real exchange rate appreciation. On the contrary, when the American demand goes up, the real exchange rate depreciates. These results are closed to those which are given by the Johansen method (Table 6). Indeed, the coefficients have the same sign and their values are nearly identical.

In addition, when tests of robustness on the residues and tests of stability of this relation are carried out, it can be stated that this relation is acceptable.

First, the residues pertaining to our empirical model are in accordance with the three required significant conditions, namely normality, stationarity and homoscedasticity (Table 6). The residues are distributed according to a normal law. Indeed, the null hypothesis of normality is accepted by the Jarque-Bera test. The stationarity of the residues is brought forth. This condition is highly useful insofar as it allows to contend that our equation is really a cointegration relation. The classical unit root PP test applied to $U(t)$ with non cointegration as the $H_{0}$ null hypothesis versus cointegration as the $H_{1}$ alternative hypothesis shows that it is impossible to accept the residues unit root null hypothesis. It follows that the residues are stationary around zero and we are to accept the cointegration $H_{1}$ hypothesis. In addition, the White procedure (1980) suggests to reject the heteroscedasticity of the residues ${ }^{6}$.

Second, we check that this specification is really stable over the considered period. It can be done through the analysis of the recursive residues of the model. If the estimated model is stable, then the recursive residues are independently and normally distributed, with zero as average and with constant standard deviation. Here the estimated long run equation is stable (chart 3). These results are supported by the CUSUM and the CUSUM of Squares tests of Brown, Durbin and Evans (1975). Indeed, the statistics we get are located within the critical band to $5 \%$ (chart 4).

\subsection{Estimating The Short Term Relation}

This VECM aims at analysing the speed of convergence of the real exchange rate towards its long term equilibrium level on one hand, the part of the fundamentals in the short run dynamics of the real exchange rate $^{7}$ on the other hand. Then the following short run relation is to be tested :

$\Delta e_{t}=\alpha U_{t-1}+A(L) \Delta e_{t-1}+B(L) \Delta t o t_{t}+C(L) \Delta y_{t}^{j a p}+D(L) \Delta y_{t}^{u s a}+E(L) \Delta r_{t}^{w}+F(L) \Delta \rho_{t}+G(L) \Delta u_{t}+W_{t}$

where $U_{t-1}=e_{t-1}-\left(0.884 t_{t o t}+0.203 y_{t-1}^{j a p}-0.221 y_{t-1}^{u s a}+0.022 r_{t}^{w}+0.641 u_{t-1}+Z_{t}-5.259\right)$ is the residue of the cointegration relation with one lag period and $A(L), B(L), C(L), D(L), E(L), F(L)$ and $G(L)$ the lag operators. This relation is to undergo two modifications. On one hand, as there are contemporaneous terms, we are to apply the Newey-West method to take into account possible heteroscedasticity by correcting the standard deviations estimated in an adequate way. On the other hand, by leaning on the Johansen method, we choose an optimal lag equal to one. Then, the final relation which is to be tested runs as follows:

$$
\begin{gathered}
\Delta e_{t}=\alpha U_{t-1}+f_{0}+f_{1} \Delta e_{t-1}+f_{2} \Delta t o t_{t}+f_{3} \Delta t o t_{t-1}+f_{4} \Delta y_{t}^{j a p}+f_{5} \Delta y_{t-1}^{j a p}+f_{6} \Delta y_{t-1}^{u s a}+f_{7} \Delta r_{t}^{w}+f_{8} \Delta r_{t-1}^{w} \\
+f_{9} \Delta \rho_{t}+f_{10} \Delta \rho_{t-1}+f_{11} \Delta u_{t}+f_{12} \Delta u_{t-1}+W_{t}
\end{gathered}
$$

\footnotetext{
6 In addition, this result is confirmed by the $\mathrm{ARCH}$ test.

7 This relation cannot be used as a forecasting model for the real exchange rate in the short run since it does not take into account the influence of the nominal and the real stationary variables.
} 
The results (Table 7) allow to contend that the short run dynamics of the real exchange rate positively depend upon the contemporaneous variations of the terms of trade and of the global productivity, and are negatively influenced by the American demand contemporaneous variations and the one period lagged variations of the terms of trade and of the Japanese demand. It matters to underline that the signs and the values of the coefficients are in accordance with those expected. We are only doubtful about the fact that the preference for the present do not drive the real exchange rate short term variations. Regarding the parameter of the adjustment speed (-0.627), two remarks can be done. First, the negative sign is the one expected. Second, its value is relatively high, suggesting that when a shock occurs the real exchange rate tends to rapidly return to its stationary long term equilibrium. Third, the $R^{2}$ of the model is not very good. It points out that the real fundamental determinants of the real exchange rate account for less than half of its quartely variance. This result is logical since the real exchange rate also depends upon the nominal variables in the short run, such as the interest rates and the money supply, without forgetting many stationary real factors previously excluded from the long run analysis, namely the differential in real interest, the public expenditures, the public deficit and the degree of openness.

Once again, the adopted specification is good. First, the tests on the residues are validated. The normality of the residues is accepted by the Jarque-Bera test, i.e. the likelihood that the null hypothesis is rejected is equal to $17.3 \%$. The non stationarity is not retained by the PP test, i.e. the computed statistics are higher than the critical values to 5\%. The homoscedasticity is accepted by the White and the ARCH tests with the likelihood to reject the null hypothesis equal to $54.9 \%$ and $68.3 \%$. The non self-correlation of the residues is validated through the tests of Durbin-Watson (DW), of Ljung-Box (LB) and of the Breusch-Godfrey (BG) multiplier of Lagrange. Second, this relation is overall stable. Indeed, the recursive residues (Chart 5) and the CUSUM and the CUSUM of squares tests (Chart 6) do not put forward other sources of instability.

\section{Calculating The Misalignment}

\subsection{The Current Misalignment}

Given the long run estimated relation, it is possible to calculate the gap between the observed real exchange rate and the equilibrium real exchange rate, i.e. the real misalignment ${ }^{8}$ (chart 7). It can be distinguished between two periods. The first one from 1976 to 1985 is marked by the Australian dollar overvaluation, whatever the used estimation method. Over this period, there are many variations in the fixed exchange rate regime. The second one begins in 1985 with the deep real and nominal depreciation in the wake of the arrival of the flexible exchange rate regime and is marked by persistent undervaluation of the local currency (according to the maximum likelihood estimation) or valuation very close to equilibrium (by means of the dynamic least squares estimation).

A significant remark can be drawn on these results. The nature of the exchange regime highly matters for the size of the misalignment in the case of the Australian economy. Indeed, when fixed exchange rate regime is underway, overvaluation tends to take place while the flexible exchange rate regime creates conditions so that overvaluation tensions are cancelled. As a result, we are tempted to contend that implementing the flexible exchange rate regime has been a good economic policy decision.

However, this contention about the efficiency of the flexible exchange rate regime should be done with caution. Indeed, the above calculus are carried out by relying on an equilibrium real exchange rate which is estimated by taking the observable values for the real fundamentals. The obtained misalignment is then a current misalignment, which cannot allow to take into account the possible gaps of these real fundamentals in relation to their potential growth path, sweeping away a significant source of instability.

\footnotetext{
8 As these two series are written under the logarithm form, the indicator of the misalignment in percentage is obtained by doing the difference between the two series (multiplied by 100).
} 


\subsection{The total misalignment}

As the above misalignment do not consider the lasting deviations of the fundamentals around their long term equilibrium, the periods of overvaluation and undervaluation are likely to be deeper. Consequently, it is worthy of interest to replace the observable values by the sustainable values which contain information about the long movements (low frequency) of the fundamentals. These sustainable variables arise once the transitory movements (high frequency) are removed from the contemporaneous series, i.e. the different kind of cycles (business cycles and seasonal movements). This decomposition is possible thanks to the Hodrick-Prescott filter (1980).

Finally, we can infer a time series for the long term equilibrium real exchange rate by introducing the sustainable values (filtered thanks to HP) of the terms of trade, the Japanese demand, the American demand, the American real interest rate, the preference for the present and the global productivity in the two long term estimated relations (through the maximum likelihood and the dynamic least squares):

$M L: \quad e_{t}^{* h p}=0.673$ tot $_{t}^{h p}+0.223 y_{t}^{j a p h p}-0.327 y_{t}^{u s a h p}+0.023 r_{t}^{w h p}-0.407 \rho_{t}^{h p}+0.670 u_{t}^{h p}-2.467$

$D L S: \quad e_{t}^{* h p}=0.890 t o t_{t}^{h p}+0.207 y_{t}^{\text {japhp }}-0.239 y_{t}^{\text {usahp }}+0.023 r_{t}^{\text {whp }}+0.699 u_{t}^{h p}-5.745$

Taking the equilibrium real exchange rate into account allows to calculate two indicators of the total real misalignment of the Australian dollar (chart 8) resulting from the gap between the observed real exchange rate and the standards of equilibrium given by (10) and (11):

$$
m i s_{t}^{h p}=e_{t}-e_{t}^{* h p}
$$

The two methods lead to the same result ${ }^{9}$. Two lessons can be drawn:

- $\quad$ On one hand, the strong real overvaluation over the period of fixed exchange rate regime is confirmed. Indeed, from 1976 to 1985 , the average real misalignment is statistically positive, with a period of marked undervaluation between 1981 and 1984 (around 15\%).

- $\quad$ On the other hand, the period of flexible exchange rate is no longer marked by persistent undervaluation of the Australian dollar. Hence, this period can be divided into five sub-periods. From 1985 to the middle of 1988, the currency is more than $10 \%$ undervalued. From 1988 to the beginning of 1992, it becomes more than 6\% overvalued. From 1992 to 1996, the currency becomes once again undervalued about 5\%. From 1996 to 1998 , the currency records overvaluation about 5\%. Finally, since 1998, it exhibits a slight trend towards undervaluation. As a result, the capacity of the flexible exchange rate regime in controlling for overvaluation pressures (even if these one are limited) must be tampered once the long term equilibrium trajectories of the fundamentals are involved in the analysis.

\section{Concluding Remarks}

Our results support the existence of a misalignment of the Australian dollar real exchange rate over 19762000. However, the magnitude of the variation in the misalignment tends to diminish since the flexible exchange rate regime has been adopted in the middle of eighties.

Dealing with the question of the influence of the real exchange rate disequilibrium on the current account, it can be noticed that the fixed exchange rate regime period is characterised by an explosive dynamic of the current account facing a strong overvaluation of the Australian dollar. This period is replaced by a convergent dynamic on the flexible exchange rate regime period during which the $\mathrm{CAD}$, although recurrent, tends to stabilise. The worsen situation occurring as soon as 1997 is to be related to the Asian crisis. 9 It must be noticed that estimating with the dynamic least squares tends to widen the misalignment, compared with the maximum likelihood
procedure. 
The convergent dynamic of the current account since the flexible exchange rate regime has been adopted and the reduction in the magnitude of the Australian dollar misalignment are the grounds we lean on in order to support the Australian current account sustainability commonly held view.

\section{References}

1. Baffes J., Elbadawi I. And O’Connell S. A (1999), "Single-Equation Estimation of the Equilibrium Real Exchange Rate", in Hinkle L. E. et Montiel P., Exchange Rate Misalignment: Concepts and Measurement for Developing Countries, Oxford University Press, New York.

2. Brown R. L., Durbin J. and Evans J. M., (1975), "Techniques for Testing the Constancy of Regression Relationships over time", Journal of the Royal Statistical Society, Series B, 37, 149-192.

3. Clark P. And McDonald R., (1998), "Exchange Rates and Economic Fundamentals: Methodological Comparison of BEERs and FEERs", IMF Working Paper, n 98/87.

4. Davidson R. And McKinnon J. G., (1993), Estimation and Inference in Econometrics, New-York, Oxford University Press.

5. Edwards S., (1989), Real Exchange Rates, Devaluation and Adjustment: Exchange Rate Policy in Developing Countries, MIT Press.

6. Edwards S., (1994), "Real and Monetary Determinants of Real Exchange Rate Behavior: Theory and Evidence from Developing Countries", in Williamson J., ed., Estimating Equilibrium Exchange Rates, Washington, D.C., Institute for International Economics.

7. $\quad$ Enders, W. (1995), Applied econometric time series, John Wiley and Sons, INC.

8. Engle, R.F. and C.W.J. Granger (1987), "Cointegration and error correction: representation, estimation and testing", Econometrica.

9. Hinkle L. E. and Montiel P., (1999), Exchange Rate Misalignment: Concepts and measurement for Developing Countries, Oxford University Press, New York.

10. Johansen, S. (1991), "Estimation and hypothesis testing of cointegration vectors in Gaussian vector autoregressive models", Econometrica, 59, pp.1551-1590.

11. Kaminsky, G., S. Lizondo, and C.M. Reinhart (1997), "Leading indicators of currency crisis", IMF Working Paper, n WP/97/79, 43p.

12. Leachman, L.L. (1998), "Intertemporal solvency in the small open economy of Australia", Economic Record, vol.74, n²26, pp.231-242.

13. Saikkonen P., (1991), “Asymptotically Efficient Estimation of Cointegration Regressions", Econometric Theory, 7, 1-21.

14. Stein J., (1994), "The Natural Exchange Rate of the US Dollar and Determinants of Capital Flows", in Williamson J., ed., Estimating Equilibrium Exchange Rates, pp. 133-176, Washington, D.C., Institute for International Economics.

15. Stein, J., P.R. Allen and Alii (1995), Fundamental determinants of exchange rate, Clarendon Press, Oxford.

16. Stock J. H. ET Watson M. W., (1988), "Variables trends in Economic Time Series", Journal of Economic Perspectives, 2, 147-174.

17. Svizzero, S. (2001), "La politique économique australienne depuis 1983. Réformes et mutations associées à l'ouverture", Géoéconomie. ("The Australian economic policy since 1983. Reforms and mutations resulting from openness").

18. Williamson J. (ed), (1994), Estimating Equilibrium Exchange Rate, Washington, D.C., Institute for International Economics.

19. Williamson J., (1983), The Exchange Rate System, MIT Press. 


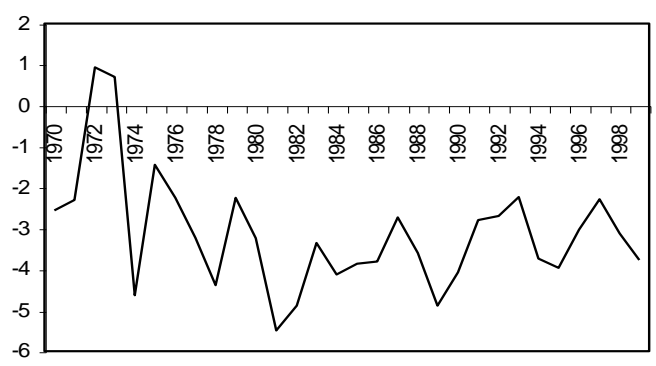

Chart 1. Current Account (\% GDP)

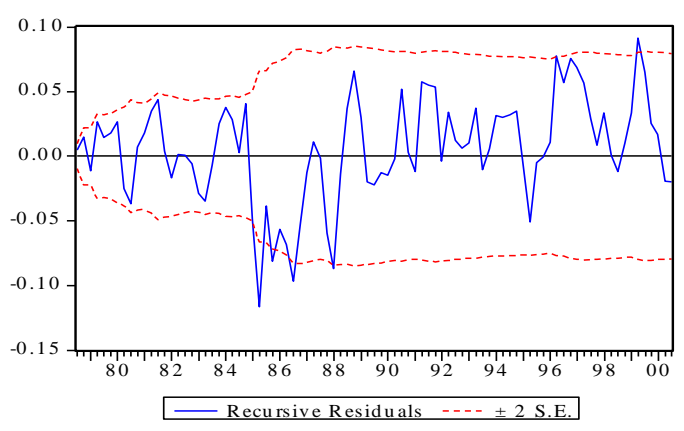

Chart 3 .Recursive residuals (Long Term)
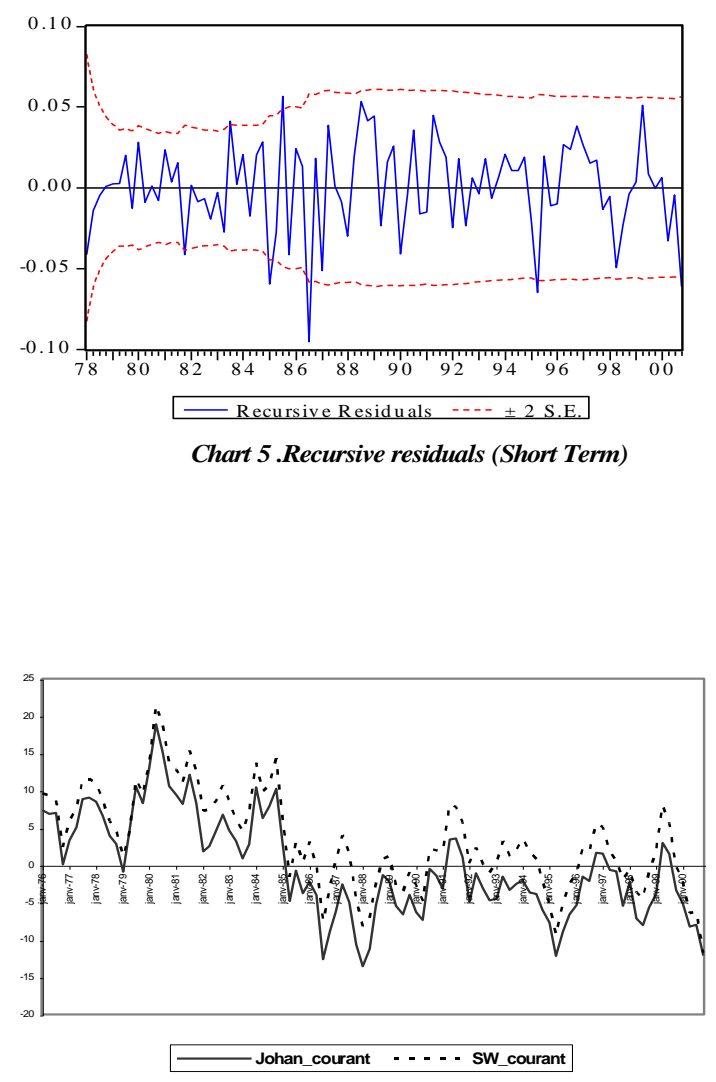

Chart 7. Johansen \& SW current misalignement

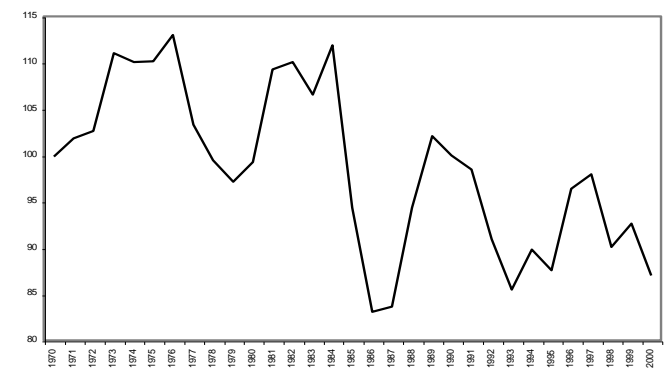

Chart 2. Real Exchange Rate
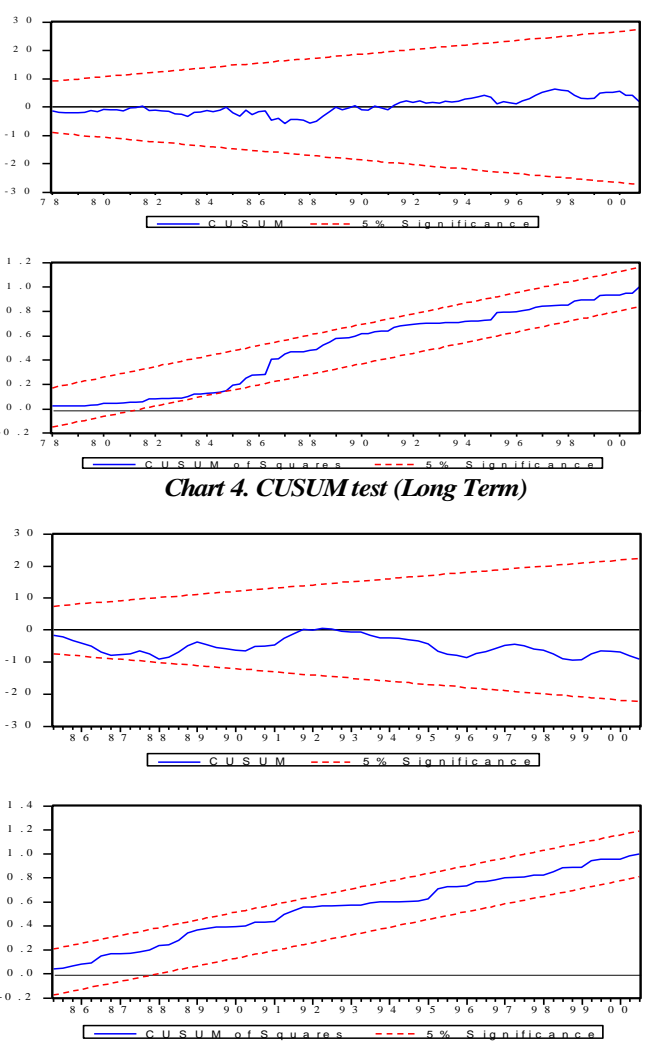

Chart 6. CUSUM test (Short Term)

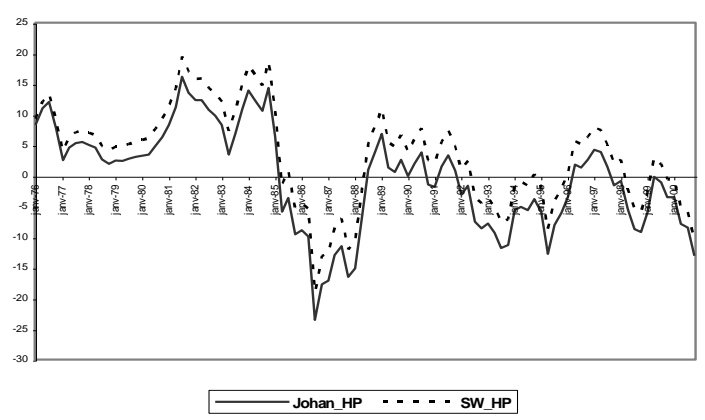

Chart 8. Johansen \& SW total misalignement ( filtred) 


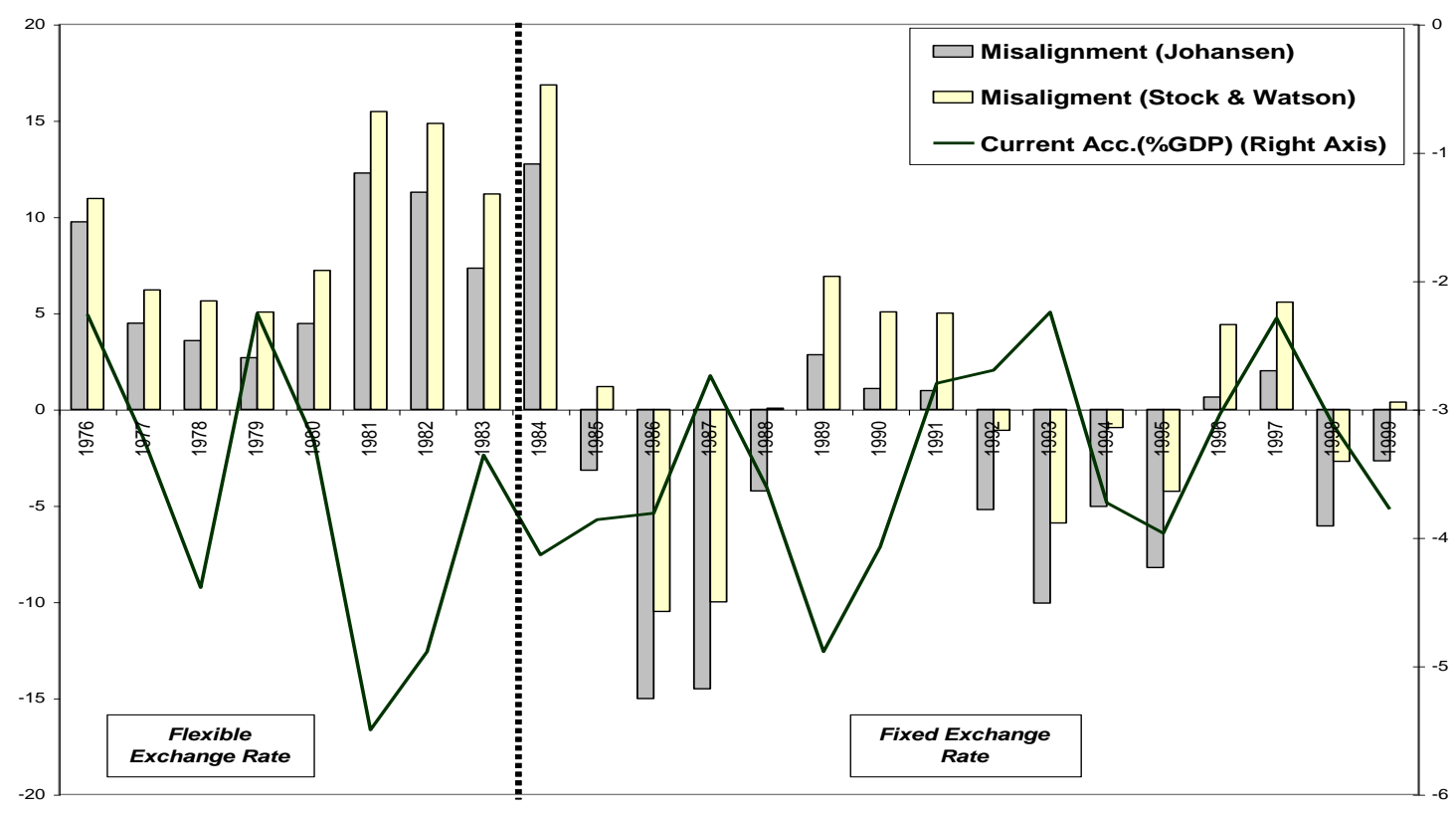

Chart 9. Current account and Misalignment 


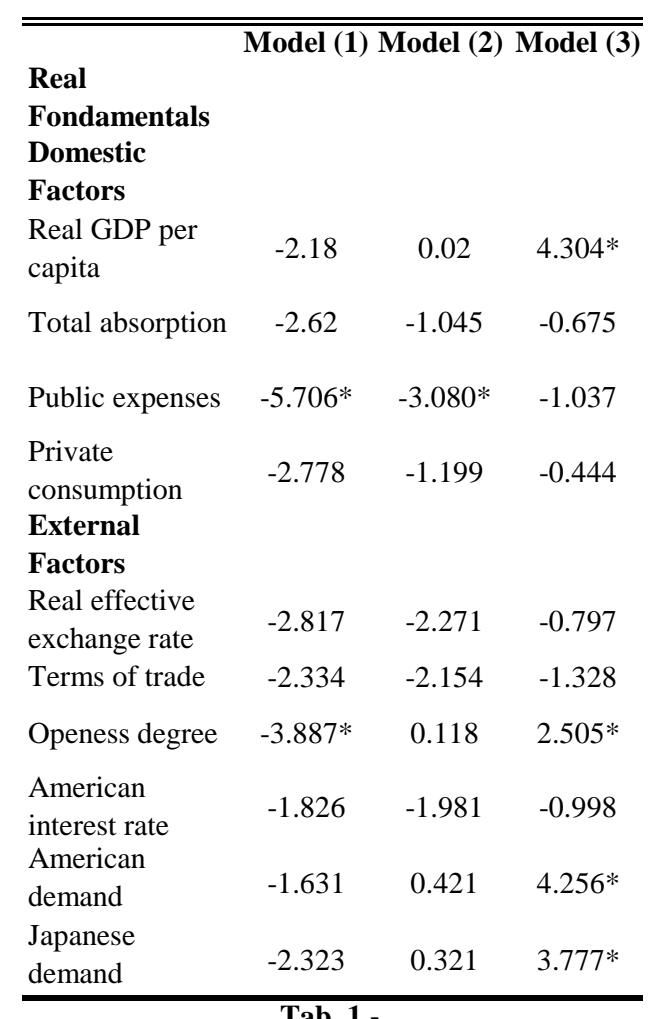

\begin{tabular}{ccc}
\hline \hline Statistic & Statistic & Statistic \\
Model (1) & Model (2) & Model (3)
\end{tabular}

Real

Fondamentals

Domestic

Factors

Real GDP per

capita

Total

absorption

$-9.394 * \quad-9.415 * \quad-8.251 *$

Private

consumption

$-13.999 *-13.827 *-13.783 *$

External

Factors

Real effective

exchange rate

Terms of trade

$-14.824^{*}-14.713^{*}-14.699 *$

American

interest rate

American

demand

Japanese

demand

\begin{tabular}{ccc}
$-9.106^{*}$ & $-9.153^{*}$ & $-9.171^{*}$ \\
$-7.681^{*}$ & $-7.589^{*}$ & $-7.471^{*}$ \\
$-8.090^{*}$ & $-8.071^{*}$ & $-8.111^{*}$ \\
$-11.253^{*}$ & $-11.145^{*}$ & $-10.127^{*}$ \\
$-12.371^{*}$ & $-12.270^{*}$ & $-11.291^{*}$ \\
\hline
\end{tabular}

Tab. 2 -

Tab. 1 -

\begin{tabular}{cccc}
\hline \hline Var $(\mathbf{p})$ & SB & AIC & LL \\
\hline $\mathbf{p = 1}$ & -24.141 & -26.147 & 1384.366 \\
$\mathbf{p = 2}$ & -22.597 & -25.879 & 1419.97 \\
$\mathbf{p = 3}$ & -21.342 & -25.901 & 1470.069 \\
$\mathbf{p = 4}$ & -19.88 & -25.715 & 1509.766 \\
\hline \multicolumn{4}{c}{ Tab. 3 - }
\end{tabular}

\begin{tabular}{ccccc}
\hline \hline Eigenvalue & LR & $\begin{array}{c}\text { Critical } \\
\text { value } \\
\text { to 5\% }\end{array}$ & $\begin{array}{c}\text { Critical } \\
\text { value } \\
\text { to 1\% }\end{array}$ & $\begin{array}{c}\text { Number } \\
\text { of CV }\end{array}$ \\
\hline 0.442 & 158.37 & 124.24 & 137.57 & Any** \\
0.362 & 100.11 & 94.15 & 103.18 & at the most $1^{*}$ \\
0.219 & 55.24 & 68.52 & 76.07 & at the most 2 \\
0.151 & 30.57 & 47.21 & 54.46 & at the most 3 \\
0.083 & 14.2 & 29.68 & 35.65 & at the most 4 \\
0.052 & 5.5 & 15.41 & 20.04 & at the most 5 \\
0.002 & 0.17 & 3.76 & 6.65 & at the most 6 \\
\hline \multicolumn{5}{c}{ Tab. 4- }
\end{tabular}




\begin{tabular}{cccccccc}
\hline \hline \multicolumn{8}{c}{ Normalized cointegration vector } \\
$e_{t-1}$ & tot $t_{t-1}$ & $y^{j a p}{ }_{t-1}$ & $y^{\text {usa }}{ }_{t-1}$ & $r^{w}{ }_{t-1}$ & $\rho_{t-1}$ & $u$ & $C$ \\
\multirow{2}{*}{1} & -0.673 & -0.223 & 0.327 & -0.023 & 0.407 & -0.67 & 2.467 \\
& $(-6.763)$ & $(-3.982)$ & $(-3.778)$ & $(-10.338)$ & $(-1.522)$ & $(-2.924)$ & \\
\hline
\end{tabular}

\section{Error correction model}

\begin{tabular}{|c|c|c|c|c|c|c|c|}
\hline VECM & $\Delta e$ & $\Delta t o t$ & $\Delta y^{j a p}$ & $\Delta y^{u s a}$ & $\Delta r^{w}$ & $\Delta \rho$ & $u$ \\
\hline \multirow[t]{2}{*}{$E C T$} & $-0.434 *$ & -0.035 & -0.142 & 0.024 & $6.036^{*}$ & 0.026 & 0.024 \\
\hline & $(-4.740)$ & $(-0.612)$ & $(-1.336)$ & $(-0.218)$ & $(-2.163)$ & $(-0.656)$ & $(-0.864)$ \\
\hline \multirow[t]{2}{*}{$\Delta e_{t-1}$} & $0.359 *$ & 0.063 & $0.310^{*}$ & -0.003 & -1.268 & -0.037 & -0.015 \\
\hline & $(-3.145)$ & $(-0.874)$ & $(-2.344)$ & $(-0.019)$ & $(-0.533)$ & $(-0.758)$ & $(-0.443)$ \\
\hline \multirow[t]{2}{*}{$\Delta t o t_{\mathrm{t}-1}$} & $-0.629 *$ & 0.172 & 0.066 & $0.468^{*}$ & -2.135 & 0.156 & -0.024 \\
\hline & $(-3.332)$ & $(-1.448)$ & $(-0.301)$ & $(-2.043)$ & $(-0.544)$ & $(-1.911)$ & $(-0.421)$ \\
\hline \multirow[t]{2}{*}{$\Delta y^{j a p}{ }_{t-1}$} & 0.029 & 0.102 & $-0.362 *$ & -0.199 & 2.214 & -0.039 & 0.029 \\
\hline & $(-0.326)$ & $(-1.793)$ & $(-3.458)$ & $(-1.816)$ & $(-1.177)$ & $(-0.989)$ & $(-1.061)$ \\
\hline \multirow{2}{*}{$\Delta y^{u s a}{ }_{t-1}$} & -0.046 & -0.09 & 0.189 & -0.132 & -2.991 & -0.033 & 0.035 \\
\hline & $(-0.524)$ & $(-1.610)$ & $(-1.844)$ & $(-1.236)$ & $(-1.628)$ & $(-0.865)$ & $(-1.312)$ \\
\hline \multirow[t]{2}{*}{$\Delta r_{t-1}^{w}$} & -0.006 & -0.003 & -0.005 & 0.006 & $0.219 *$ & -0.002 & 0.002 \\
\hline & $(-1.263)$ & $(-0.972)$ & $(-0.808)$ & $(-1.049)$ & $(-2.112)$ & $(-0.765)$ & $(-1.085)$ \\
\hline \multirow[t]{2}{*}{$\Delta \rho_{t-1}$} & -0.098 & 0.116 & 0.051 & -0.341 & -7.335 & $-0.438^{*}$ & -0.085 \\
\hline & $(-0.437)$ & $(-0.822)$ & $(-0.196)$ & $(-1.253)$ & $(-1.572)$ & $(-4.528)$ & $(-1.261)$ \\
\hline \multirow[t]{2}{*}{$\Delta u_{t-1}$} & 0.612 & $0.504 *$ & 0.618 & 0.141 & -0.066 & $-0.394 *$ & 0.055 \\
\hline & $(-1.768)$ & $(-2.305)$ & $(-1.54)$ & $(-0.336)$ & $(-0.009)$ & $(-2.634)$ & $(-0.524)$ \\
\hline \multirow[t]{2}{*}{$\mu_{0}$} & $-0.024 *$ & -0.005 & 0.011 & $0.025^{*}$ & 0.16 & 0.002 & $0.005^{*}$ \\
\hline & $(-4.056)$ & $(-1.311)$ & $(-1.563)$ & $(-3.52)$ & $(-1.311)$ & $(-0.737)$ & $(-2.676)$ \\
\hline \multirow[t]{2}{*}{$D^{r e g}$} & $-0.046^{*}$ & -0.001 & 0.006 & -0.008 & -0.42 & 0.002 & -0.004 \\
\hline & $(-3.944)$ & $(-0.127)$ & $(-0.432)$ & $(-0.535)$ & $(-1.740)$ & $(-0.319)$ & $(-1.072)$ \\
\hline$R^{2}$ & 0.27 & 0.19 & 0.2 & 0.17 & 0.22 & 0.24 & 0.1 \\
\hline$P P$ & -10.34 & -10.48 & -10.37 & -9.917 & -10.23 & -9.776 & -9.847 \\
\hline $\begin{array}{c}\text { Jarque - } \\
\text { Bera }\end{array}$ & 3.82 & $7.008^{*}$ & 1.431 & 0.758 & 4.061 & $11.747 *$ & 6.2 \\
\hline$L M(2)$ & 1.701 & 2.177 & 3.412 & 1.919 & 2.902 & 0.353 & 2.39 \\
\hline$L M(4)$ & 6.997 & 3.639 & $14.956^{*}$ & $18.134 *$ & 7.678 & 0.846 & 4.84 \\
\hline
\end{tabular}

Tab. 5 -

\begin{tabular}{|ccccccccc}
\hline \hline \multicolumn{8}{c}{ Long-term relation } \\
$e_{t}$ & tot ${ }_{t}$ & $y^{j a p}{ }_{t}$ & $y^{u s a}{ }_{t}$ & $r^{w}$ & $u_{t}$ & $\mu_{0}$ & $\sum_{j=-p}^{p} \Delta y_{t-j}^{f}$ \\
1 & $0.884^{*}$ & $0.203^{*}$ & $-0.221 *$ & $0.022^{*}$ & $0.641 *$ & -5.259 & $\mathrm{C} *_{\mathrm{j}}$ \\
$t$-stat & $(-12.24)$ & $(-3.81)$ & $(-4.41)$ & $(-8.185)$ & $(-3.637)$ & $(-3.606)$ & $()$. \\
\hline
\end{tabular}

\section{Validity tests of the relation}

$R^{2} \begin{gathered}\text { Jarque - } \\ \text { Bera }\end{gathered}$

$\begin{array}{llllll}0,889 & 0.328 & 3.692 & 85.114 & -6.175 & -6.014\end{array}$

$\begin{array}{llllll}p \text {-value } & -0.849 & -0.159 & -0.809 & (*) & (*)\end{array}$

* Critical values can be obtained in Davidson and Mackinnon (1993).

Tab. 6 -

\begin{tabular}{|c|c|c|c|c|c|}
\hline \multicolumn{6}{|c|}{ Short-term relation } \\
\hline$\Delta e_{t}$ & $U_{t-1}$ & $\Delta e_{t-1}$ & $\Delta t_{t o t}$ & $\Delta$ tot $_{t-1} \Delta y^{j a p}{ }_{t-1} \Delta y^{u s a}{ }_{t}$ & $\Delta u_{t}$ \\
\hline 1 & $-0.603 *$ & $0.339 *$ & $0.697 *$ & $-0.487 *-0.144 *-0.198 *$ & $0.552 *$ \\
\hline t-stat & $(-7.616)$ & $(-3.292)$ & $(-3.522)$ & $(-2.992)(-2.22)(-2.483)$ & $(-1.92)$ \\
\hline
\end{tabular}

\section{Validity tests of the relation}

$\begin{array}{ccccccc}R 2 & \text { DF } & \begin{array}{c}\text { Jarque- } \\ \text { Bera }\end{array} & \text { LM(10) } & \text { White } & \text { ADF } & P P \\ 0.471 & 2.141 & 2.721 & 14.018 & 34.146 & -10.62 & -10.6 \\ & \text { p-value } & -0.256 & -0.172 & -0.509 & (*) & (*)\end{array}$

*Critical values can be obtained in Davidson and MacKinnon (1993).

Tab. 7 -

\begin{tabular}{ccccccccccc}
\hline \hline$p$ & 1 & 2 & 3 & 4 & 5 & 6 & 7 & 8 & 9 & 10 \\
$Q L B$ & 1.089 & 1.38 & 1.989 & 7.413 & 7.718 & 9.314 & 9.363 & 9.511 & 9.691 & 10.17 \\
$p$-value & 0.297 & 0.502 & 0.575 & 0.116 & 0.172 & 0.157 & 0.228 & 0.301 & 0.376 & 0.425 \\
\hline \hline
\end{tabular}

Tab. 8 - 